\title{
First Report of Chromosome Number in Four Taxa Belonging to the Genus Chara Linn.
}

\author{
L. Labh and B. N. Verma \\ Phhycological Laboratory, Department of Botany, University \\ of Bihar, Muzaffarpur-842 001, India
}

Accepted October 17, 1983

Common occurrence and big size of the chromosomes in Chara have made it an ideal material for the nuclear cytology. Taking this privilage, the chromosome numbers in as many as 51-taxa belonging to this genus have been reported so far (cf. Lindenbein 1972, Hotchkiss 1958 and 1963, Guerlesquin 1961 and 1967, Khan and Sarma 1967, Noor 1965, Ramjee 1968, Chatterjee 1971, Verma 1974, Sinha and Verma 1970, Ramjee and Bhatnagar 1978, Noor and Mukherjee 1977, Griffin and Proctor 1964, Tindal and Sawa 1964). However, the number of investigated taxa is pretty less compared to the number of taxa known under this genus. In the present communication, chromosome numbers have been reported in such four taxa of Chara which do not bear any previous report on this line.

\section{Materials and methods}

The four taxa under study were collected from three districts of North Bihar where they were growing in the temporary pools during different seasons of the years (cf. Table 1). Indentification of the taxa have been done as per Wood and Imahori (1965).

Fixation of the healthy vegetative filaments bearing antheridia was made on the collection spot during the morning hours (8-10 A.M.). Acetic-ethanol (1:1) was used as the fixative and iron-alum-acetocarmine method (cf. Grodward 1948) was adopted for cytological preparations.

The chromosome numbers were ascertained in the actively dividing antheridial filaments.

\section{Observations and discussion}

In the present investigation, a count of 14 chromosomes has been ascertained for C. braunii f. cormandelina (Fig. 1), 28 for $C$. vulgaris var. nitelloides (Fig. 2) as well as for $C$. zeylanica var. zeylanica f. trichantha (Fig. 3) and 42 for C. setosa f. intermis (Fig. 4). From the available literatures it appears that the chromosome number has not been reported so far in any of the above noted four taxa. Therefore, the present counts are first record for the respective taxa.

The chromosome numbers reported so far in this genus are in multiple of 7 i.e. $7,14,28,35,49,56$ and 70 (vide infra). Three chromosome numbers ascertained 
by the authors also confirm the above series. It is further evident from the literatures that there has been a large scale variations of chromosome nubmer both at interspecific as well as at intraspecific level and thus it does not seem to be of taxono-
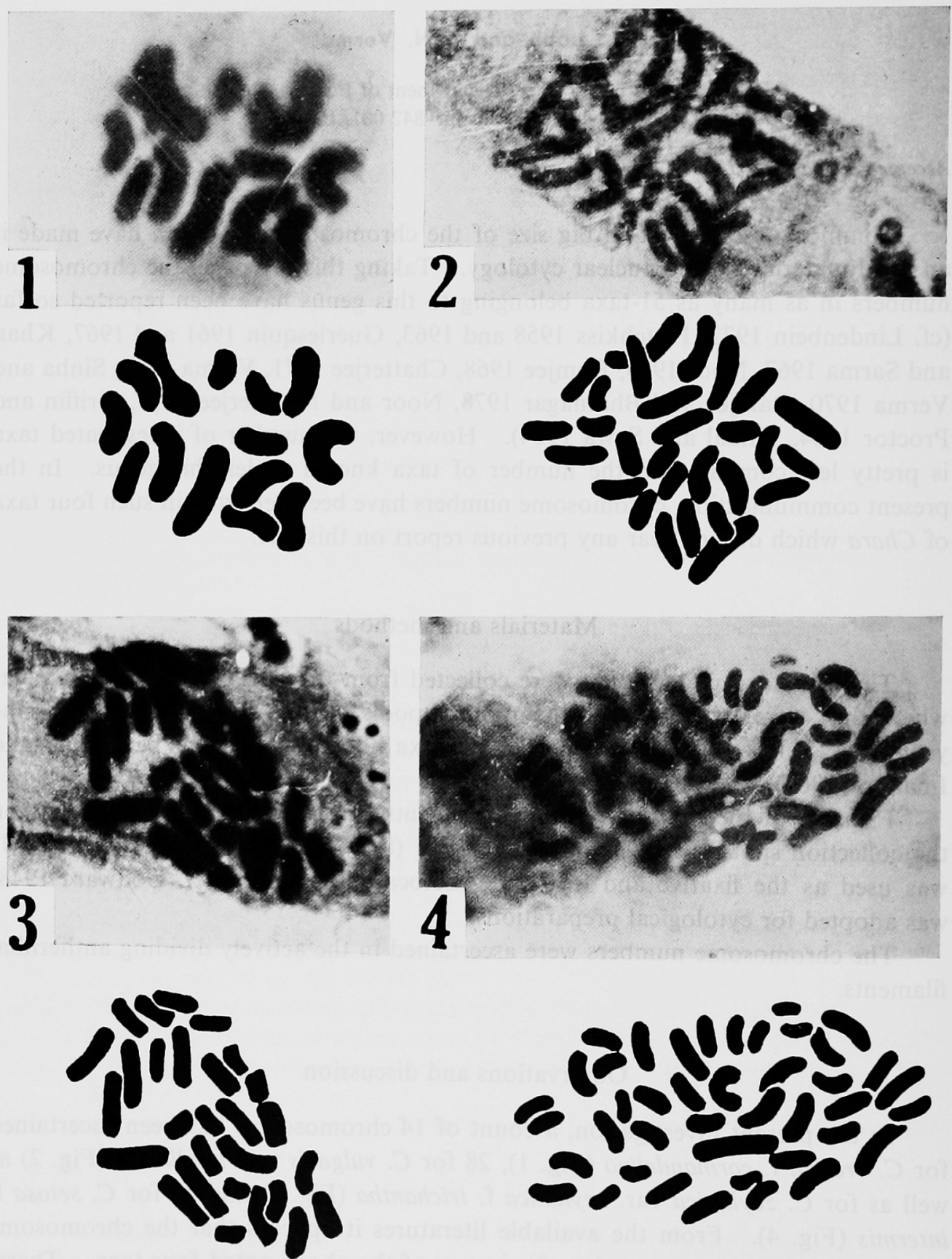

Figs 1-4. Metaphase plates showing countable chromosomes. 1, C. braunii f. cormandelina-14 $\times 5000$. 2, C. vulgaris var. nitelloides $-28 . \times 3000.3$, C. zeylanica var. zeylanica $\mathrm{f}$. trichantha -28. $\times 3200$. 4, C. setosa f. intermis $-42 . \times 3700$. Below: each photographs are their outline drawings. 
mic importance.

Out of the 71-euploid counts reported so far among 51 investigated taxa, the frequency of the chromosome number 14 has been calculated about $40 \%$ and that of 28 and 42 as $24 \%$ and $17 \%$ respectively. Therefore, it may be safely concluded that the 14 is the most common count for the genus and that of 28 is next to it.

\section{Summary and conclusions}

Four taxa belonging to the genus Chara have been cytologically investigated and the chromosome numbers have been ascertained as 14 for $C$. braunii f. cormandelina, 28 for C. vulgaris var. nitelloides and C. zeylanica var. zeylanica f. trichantha and 42 for $C$. setosa $\mathrm{f}$. intermis. The four investigated taxa bear no previous report of chromosome numbers and hence the present counts are the maiden reports.

Table 1.

\begin{tabular}{clll}
\hline S1. & \multicolumn{1}{c}{ Name of the taxa } & Place of collection & \multicolumn{1}{c}{$\begin{array}{l}\text { Time of } \\
\text { collection }\end{array}$} \\
\hline No. & & & January \\
& C. braunii f. cormandelina & University campus, & 1978 \\
& (A. Br.) Zanev. R.D.W. & Muzaffarpur & March \\
2 & C. vulgaris var. nitelloides & Kumarbag, West & 1977 \\
& (A. Br.) R.D.W. & Champaran & November \\
3 & C. zeylanica var. zeylanica f. & Ram Dayalu Nagar, & 1977 \\
& trichantha (A. Br) H. and J. Gr. R.D.W. & Muzaffarpur & December \\
4 & C. setosa f. intermis R.D.W. & Madhubani & 1977 \\
& & & \\
\hline
\end{tabular}

\section{Acknowledgements}

Authors express their deep sense of gratitude to Dr. S. S. Prasad, Professor and Head, Department of Botany, University of Bihar, Muzaffarpur (Bihar, India) for extending laboratory facilities.

\section{References}

Chatterjee, P. 1971. An analysis of the structure and behaviour of chromosomes of certain higher and lower groups of plants and the cytological effects of certain physical and chemical agents in the latter. Ph. D. Thesis, Calcutta University.

Godward, M. B. E. 1948. The iron-alum-acetocarmin method for algae. Nature 161: 203.

Griffin, W. and Proctor, V. W. 1964. A population study of Chara zeylanica in Texas, Okulahoma and New Mexico. Amer. J. Bot. 51: 120-124.

Guerlesquin, M. 1961. Contribution à l'étude chromosomique des Chraophycées d'Europe occidentale et d'Afrique du Nord. Rev. Gen. Bot. 68: 360-372.

- 1967. Recherches caryotypiques et cytotaxonomiques chez les Charophycées d'Europe occidentale et d'Afrique du Nord. Ph. D. Thesis (France).

Hotchkiss, A. T. 1958. Some chromosome numbers in Kentucky Characeae. Trans. Kentucky Acad. Sci. 19: 39-48. 
- 1963. A first report of chromosome numbers in charophyte genus Lychnothamus (Rupr.) Leonh. and comparison with the other charophyte genera. Proc. Linn. Soc. New South Wales 138: 368-372.

Khan, M. and Sarma, Y. S. R. K. 1976. Studies on cytotaxonomy of Indian Charophyta I. Chara. Phykos 6(1 and 2): 36-47.

Lindenbein, W. 1972. Beitrag zur Cytologie der Charales. Planta 4: 436-466.

Noor, M. N. 1965. Cytotaxonomic and cultural studies of some members of Chlorophyceae of Chhotanagpur, Ph. D. Thesis. Ranchi University, Ranchi (Bihar).

- and Mukherjee, S. 1977. Some new records of chromosome numbers in India charophyta. Cytologia 42: 227-232.

Ramjee 1968. Contributions to the systematics, cytology and cytotaxonomy of Indian Charophyta. Ph. D. Thesis B.H.U.

- and Bhatnagar, S. K. 1978. Studies on charophytes from Rohilkhand Division I. Moradabad: Taxonomic enumeration and chromosome counts. Phykos 17(1 and 2): 87-92.

Sinha, J. P. and Verma, B. N. 1970. Cytological analysis of the charophytes of Bihar. Phykos 9(2): 92-99.

Tindal, D. R. and Sawa, T. 1964. Chromosomes of the Characeae of the Wood's Mole (Marachusetts) region. Amer. Jour. Bot. 51 : 943-949.

Verma, S. 1974. Ph. D. Thesis, Ranchi University.

Wood, R. D. and Imahori, K. 1965. A Revision of the Characeae. Monograph and Iconograph, Verlag von J. Cramer. Publication. 